\title{
Temperature Dependence of Electrophysiological Responses of Lepidopteran Antennae*
}

\author{
Hans Jürgen Bestmann and Klaus Dippold \\ Institut für Organische Chemie der Universität Erlangen-Nürnberg, \\ Henkestraße 42, D-8520 Erlangen, Bundesrepublik Deutschland \\ Z. Naturforsch. 44c, 333-344 (1989); received January 31, 1989 \\ Dedicated to Professor Achim Trebst on the occasion of his 60th birthday
}

Electroantennogram, Electrosensillogram, Optimum Curves, Hysteresis,

Temperature Dependence

By recording the temperature dependence of electroantennograms with Lepidoptera antennae optimum curves were obtained, and a hysteresis phenomenon was observed by passing temperature cycles. The latter also occur with single cell recording (electrosensillogram) in the receptor potentials as well as in the number of action potentials released per second. The results of the measurements are discussed on a molecular level, a scheme reflects the molecular processes which eventually are involved in the interaction of a signal molecule and receptor region.

A model based on structure activity relationships has been proposed in order to explain how pheromone molecules interact with the receptor regions at the dendrite membranes of Lepidoptera [3, 4]. According to this model the pheromone molecule is inserted into the whole receptor region in a flexible manner, in which the pheromone is lying in a defined conformation in the final stage. This process and the molecular consequences resulting from it, which gives rise to the opening of ion channels, is expected to show a temperature dependence. This phenomenon can be studied by monitoring the temperature dependence of electroantennogram and electrosensillogram responses. Hitherto, investigations of this kind have not been carried out with antennae of Lepidoptera. We report here the results of such an investigation.

\section{Material and Methods}

\section{Material}

The lepidopteran species Agrotis segetum and Mamestra brassicae used in this study were from lab-

Abbreviations: EAG, electroantennogram; ESG, electrosensillogram.

* Pheromones 70 [1]. See also the preceding paper [2].

Reprint requests to Prof. Dr. H. J. Bestmann.

Verlag der Zeitschrift für Naturforschung, D-7400 Tübingen $0341-0382 / 89 / 0500-0333 \$ 01.30 / 0$ oratory colonies from the Hoechst AG, Frankfurt; Manduca sexta were from J. G. Hildebrand, Columbia University of New York; Antheraea polyphemus from the Max-Planck-Institute for Behavioral Physiology, Seewiesen; Antheraea pernyi was provided from Prof. Chen Te-Ming, Department of Biology, Beijing University, PR China.

\section{Methods}

Electroantennography (EAG) and electrosensillography (ESG)

The electroantennogram (EAG) measurements were carried out according to the description of Schneider [5], and the electrosensillogram (ESG) technique according to that of Kaissling [6, 7]. (Electrode filled with a $20 \%$ solution of polyvinylpyrrolidone K 90 (Fluka AG) in receptor lymphe Ringer's solution [7].)

\section{Apparatus}

For the investigation of the temperature dependence of EAG and ESG responses, a computer-controlled apparatus was developed, as presented schematically in Fig. 1. In this set-up, the airstream blown over the antenna, to which for stimulation a defined amount of a pheromone can be mixed, could be heated or cooled gradually. The system was controlled by a computer (Commodore 4), which stored and provided the pre-set values and the rate of 


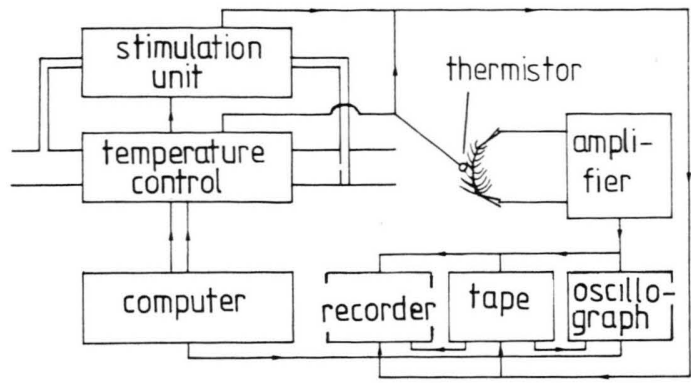

Fig. 1. Schematic presentation of the apparatus.

changing of temperature to the controlling circuit. This computer also regulated the time program which controlled the duration of stimulation.

\section{Temperature controlling}

The following procedures were used to heat or cool the air used (Fig. 2): The antennal preparate was positioned in a continuous stream of air (1) of $200 \mathrm{ml}$ per sec. The air flow was measured with a rotameter (2). The continuous air stream was cooled to $-30{ }^{\circ} \mathrm{C}$ by Peltier elements ( 3 ) and heated to the desired temperature by a platinum wire (4). The temperature of the preparate was measured by a thermistor (5) placed near the antenna. The computer-controlled unit could read this value and adjust the temperature to the pre-set value by means of the heating coil.

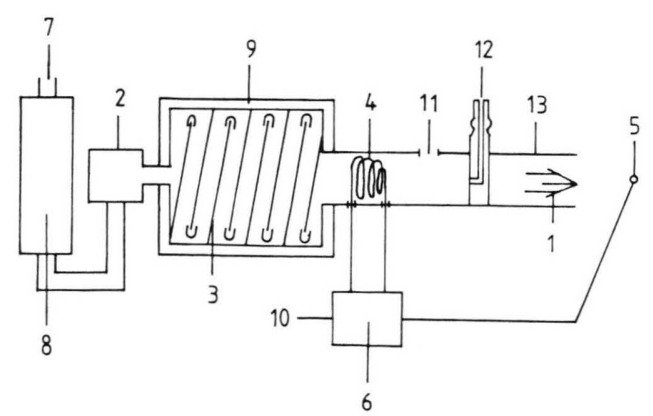

Fig. 2. Illustration of the temperature control unit. (1) Continuous air stream, (2) rotameter, (3) cooling elements, (4) heating coil, (5) thermistor, (6) temperature controller, (7) pressurized air, (8) charcoal filter, (9) plastic body, (10) nominal value input, (11) ESG stimulation input, (12) EAG stimulation input, (13) glass tube.

\section{EAG stimulation}

To provide the stimulations for EAG recordings the following arrangements were made (Fig. 3):

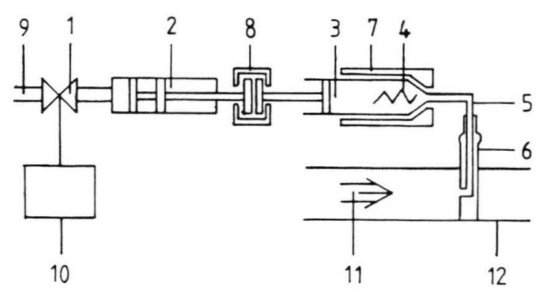

Fig. 3. A schematic drawing of the stimulation arrangement for the EAG recordings. (1) Valve, (2) pneumatic cylinder, (3) one-way syringe, (4) filter paper, (5) silicone tubing, (6) brass metal piece, (7) injector holding, (8) interface syringe-cylinder, (9) pressurized air, (10) valve control circuit, (11) continuous air stream, (12) glass tube.

The motion of the plunger of a disposable syringe (3) was controlled by an electrically operated valve (1), which regulated the pneumatic cylinder (2). In the syringe a piece of filter paper (4) loaded with the stimulant was placed. When the plunger was withdrawn an odour cloud is generated inside the barrel. The concentration in this cloud depends on the length of time the plunger is kept withdrawn and on the temperature. Since the intervals between each puff and all the other conditions were kept constant, the concentration of the stimulus may be expected to be constant within a test series. This was confirmed experimentally by the fact that the same EAG amplitudes were obtained for repeated stimulations conducted at a constant temperature. The stimulations were provided by pushing forward the plunger of the syringe. This provided a 8 -ml-per-sec mixture of air and pheromone stimulus chemical mixture, which was mixed via a $5-\mathrm{cm}$ piece of silicone tubing held by the brass nut (6). Afterwards the plunger was automatically drawn up to the original position. The odour molecules which did not reach the antenna were vented by an exhaust system.

\section{Stimulations for ESG}

In order to provide constant quantities of stimulus per second for relatively longer periods, the equipment for the stimulation for ESG measurements was changed in the following way (Fig. 4): 


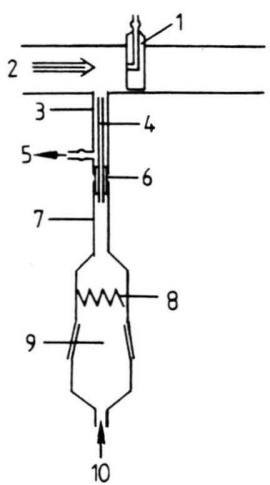

Fig. 4. Sketch of the stimulation arrangement for the ESG recordings. (1) Brass metal piece $5 \times 5 \mathrm{~cm}$, (2) continuous air stream, (3) glass tubing, $60 \mathrm{~mm}, 3.5 \mathrm{~mm}$ ID, (4) glass capillary, $65 \mathrm{~mm}, 1.0 \mathrm{~mm}$ ID, (5) exhaust orifice, (6) silicone tubing, (7) glass tube, $100 \mathrm{~mm}, 3.5 \mathrm{~mm}$ ID, (8) folded filter paper, (9) ground-glass joint, (10) opening for cleaned pressurized air.

A folded piece of filter paper $(8,2 \mathrm{~cm} \times 6 \mathrm{~cm})$ was loaded with the stimulus and placed in the container which can be opened through the ground-glass joint (9). The female end of the connection ended in a narrow glass tube (7) which was connected to the glass capillary (4) by a piece of silicone tubing (6). The silicone tube (6) also held the second glass tube (3) with side opening (5). Through this opening, air was continuously vented in order to purge out the odour molecules which may diffuse from the glass capillary. This way contamination of the preparation was avoided. One end of this glass tube (3) was inserted into the glass cylinder (2) through which the continuous air stream was flowing. The stimulation was provided by blowing a defined amount of air containing the pheromone, through the open end (10).

It should be noted that by adding small amounts of stimulus chemicals into the continuous air stream, which is about fifty times greater, the amount of stimulus experienced by the antenna is considerably reduced. Thus, a loading of $0.1 \mu \mathrm{g}$ corresponds to an effective stimulus loading of about $0.002 \mu \mathrm{g}$, providing a linear relationship between evaporation respectively desorption of the stimulus molecule and the load.

With an intact antennal preparation, control experiments were conducted under identical test conditions but without a stimulus chemical (syringe not loaded). Hereby the changes of pressure and temperature, possibly generated by the movement of the plunger, could be excluded. The electronic noise generated by the system was smaller than $0.1 \mathrm{mV}$.

\section{Results}

\section{Optimum curves}

With a stimulation time of $1 \mathrm{sec}$ the EAG amplitudes given by all the insects species tested in this study showed a temperature dependence which went through a maximum. Fig. 5 shows the results obtained from five different species; the concentration of the stimulus at the source was kept constant for each measuring cycle.

In all the experiments the antenna was first adapted to a temperature of $15^{\circ} \mathrm{C}$. Then the temperature was either raised or lowered continuously in the range between 0 and 30 or $35^{\circ} \mathrm{C}$. The rate of
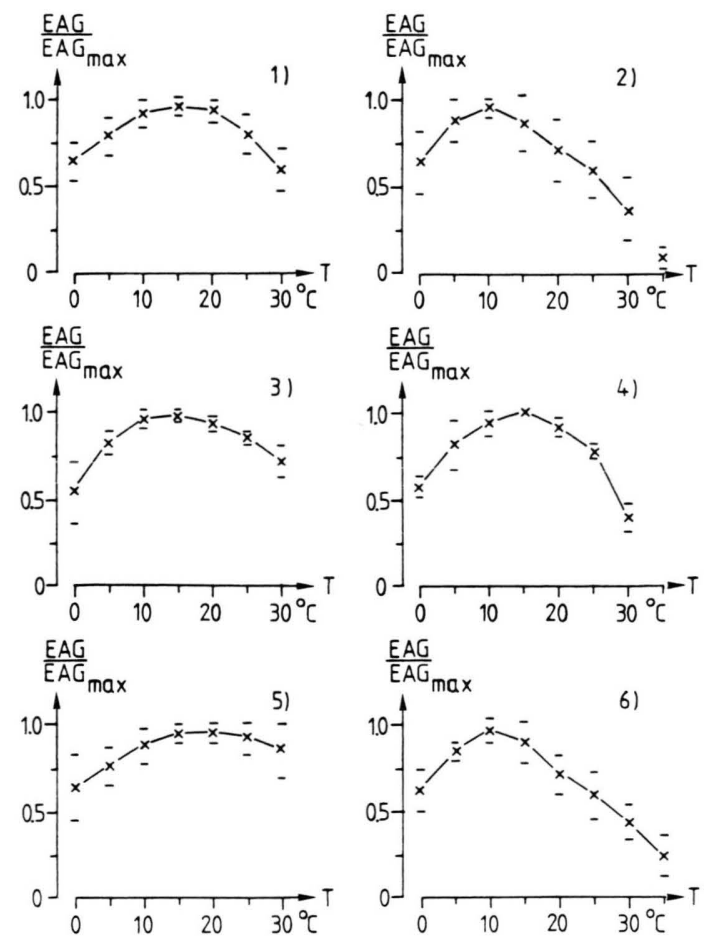

Fig. 5. Dependence of EAG amplitudes on the temperature with various lepidopteran species. Presented average values and standard deviations. Stimulation period: $1 \mathrm{sec}$; stimulation intervals: $60 \mathrm{sec}$; 1) Agrotis segetum: $1.0 \mu \mathrm{g} \mathrm{(Z)-}$ 5-decenyl acetate; 2) Antheraea pernyi: $0.1 \mu \mathrm{g}(E)-6,(Z)-11$ hexadecadienal; 3) A. polyphemus: $1.0 \mu \mathrm{g}(E)-6,(Z)-11$ hexadecadienyl acetate; 4) $A$. polyphemus: $0.1 \mu \mathrm{g}(E)$ 6,(Z)-11-hexadecadienal; 5) Mamestra brassicae: $10.0 \mu \mathrm{g}$ (Z)-11-hexadecenyl acetate; 6) Manduca sexta: $0.1 \mu \mathrm{g}(E)$ 10,(Z)-12-hexadecadienal. 
change of temperature was normally $5{ }^{\circ} \mathrm{C} / \mathrm{min}$, and the electroantennograms were recorded at each $5{ }^{\circ} \mathrm{C} /$ step.

Identical results were obtained when the experiment was carried out with a stepwise temperature program in which the temperature changes were carried out for e.g. $5{ }^{\circ} \mathrm{C}$ in $5 \mathrm{sec}$, after the new temperature was held for $40 \mathrm{sec}$, the stimulation was provided and then progressed to the next temperature step.

\section{Hysteresis}

A hysteresis phenomenon was observed in the following experiments. First the antennal preparation was adapted to a temperature of $15{ }^{\circ} \mathrm{C}$, and then continuously cooled to $0^{\circ} \mathrm{C}$. Subsequently, the temperature was increased from $0{ }^{\circ} \mathrm{C}$ to $35^{\circ} \mathrm{C}$, and afterwards the temperature was decreased again to $0{ }^{\circ} \mathrm{C}\left(5^{\circ} \mathrm{C} /\right.$ min, Fig. 6). During this process the antenna was stimulated every minute by a constant amount of pheromone.

Fig. 7 shows that the optimum curves obtained for descending temperature $\left(30\right.$ to $\left.0{ }^{\circ} \mathrm{C}\right)$ were over those obtained for increasing temperature $\left(0\right.$ to $\left.30^{\circ} \mathrm{C}\right)$. Consequently, for each temperature two values were obtained depending on the temperature pretreatment of the antenna (cold or hot pre-temperature, respectively), i.e. with cyclic temperature programs a hysteresis is observed.

Fig. 7 reflects a typical curve obtained from Antheraea pernyi. It can be recognized that for higher concentrations of the stimulus, the differences between the EAG amplitudes for a certain temperature is greater than the differences for lower concentrations.

The hysteresis effect observed here, with continuous changing of temperature, could have been caused at least partly, due to a lag in the temperature actually experienced by the antennae. In order to minimize such an effect, in the following experiments a stepwise temperature program was chosen. The preparation, after each temperature jump, which required $20 \mathrm{sec}$, was allowed to adapt to the new tem-

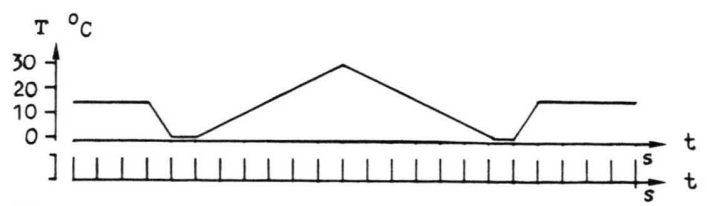

Fig. 6. Temperature and stimulation program.

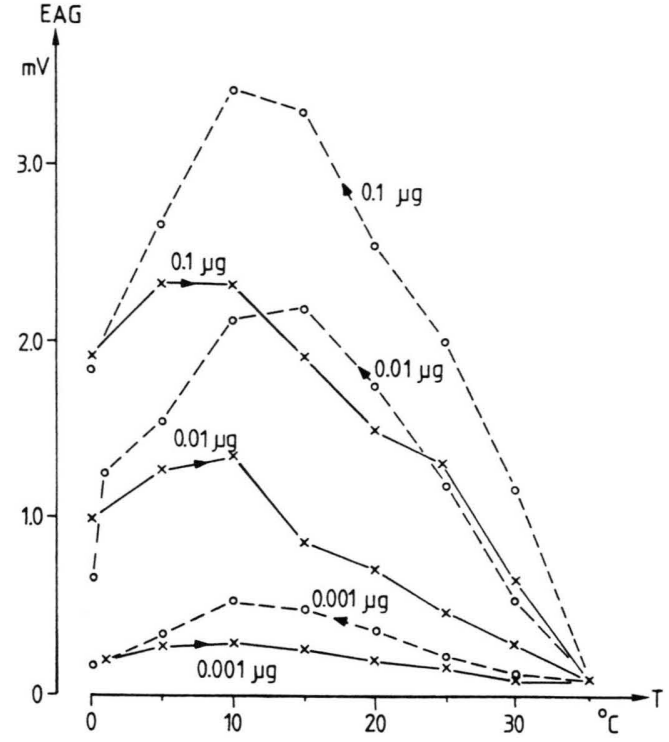

Fig. 7. Temperature dependence of electroantennogram amplitudes, determined with continuously temperature change according to Fig. 6 with Antheraea pernyi. The EAG amplitudes marked $\times \longrightarrow \times$ characterize the values obtained with recordings with increasing temperature, the values marked $\bigcirc---\bigcirc$ those with decreasing temperature. Sequence of stimulus source loading: 0.001, 0.01, $0.1 \mu \mathrm{g}(E)-6,(Z)-11$-hexadecadienal; duration of stimulation: $1 \mathrm{sec}$; stimulation interval: $60 \mathrm{sec}$.

perature for $180 \mathrm{sec}$. Afterwards, it was stimulated; the stimulus interval as well as the stimulus loading were kept constant within a test series. Fig. 8 shows the mean values obtained out of four recording cycles.

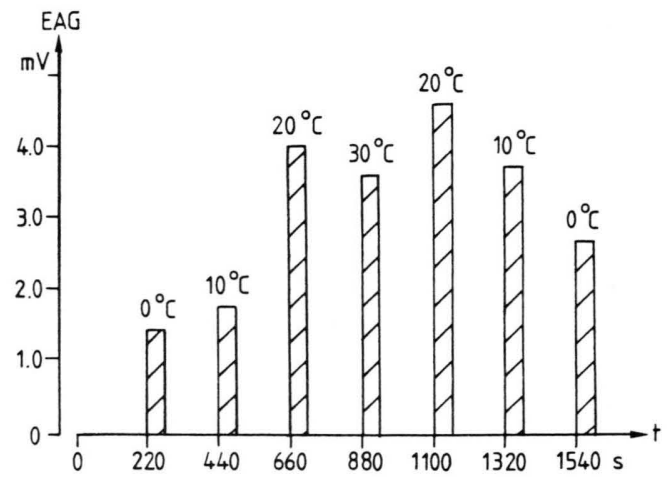

Fig. 8. Temperature dependence of EAG amplitudes with stepwise temperature changes, recorded with Agrotis segetum. Stimulus source loading: $1.0 \mu \mathrm{g}(Z)$-5-decenyl acetate; stimulus period: $1 \mathrm{sec}$, stimulation interval: $220 \mathrm{sec}$. The column diagram reflects mean values out of four measuring cycles. 
Also with this temperature program a clear hysteresis effect can be seen. The values measured for warm temperature pretreatment always lie over those for cold.

\section{Temperature dependence of the course} of EAG responses

Not only the amplitude, but also the temporal course of the EAG responses is temperature-dependent. In order to study these effects the following factors were defined (Fig. 9): $\tau / 2$ means the halfwidth of the EAG signal, $\tau / 2 \downarrow$ the half time of rise and $\tau / 2 \uparrow$ that for decline.

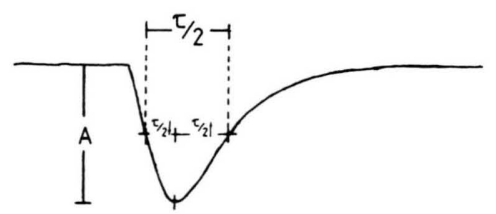

Fig. 9. EAG showing the defined terms. A: Maximum of the EAG amplitude; $\tau / 2$ : half-width of EAG; $\tau / 2 \downarrow$ : halftime of rise; $\tau / 2 \uparrow:$ half-time of decline.

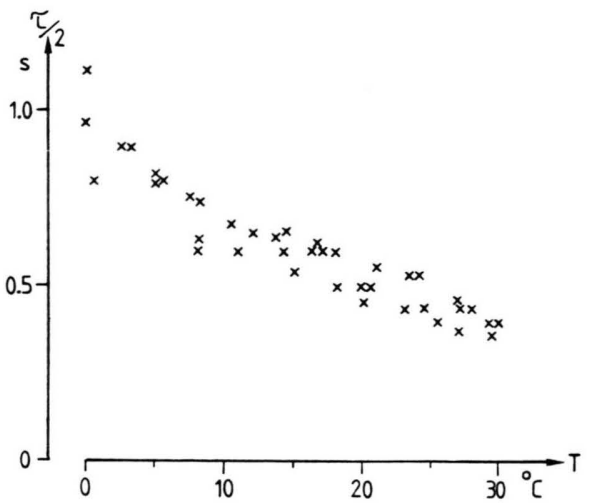

Fig. 10. Temperature dependence of EAG half-width $\tau / 2$, obtained with Agrotis segetum; stimulus period: $1.0 \mathrm{sec}$; stimulation interval $60 \mathrm{sec}$; stimulus source: $1.0 \mu \mathrm{g}(Z)-5-$ decenyl acetate. A few temperature cycles were measured.

With increasing temperature the $\tau / 2$-value decreases, as illustrated in Fig. 10.

From Fig. 11 it is evident that the declining phase is mainly responsible for the lower $\tau / 2$-values observed with higher temperatures. The influence of the $\tau / 2 \downarrow$-values could not be observed precisely.

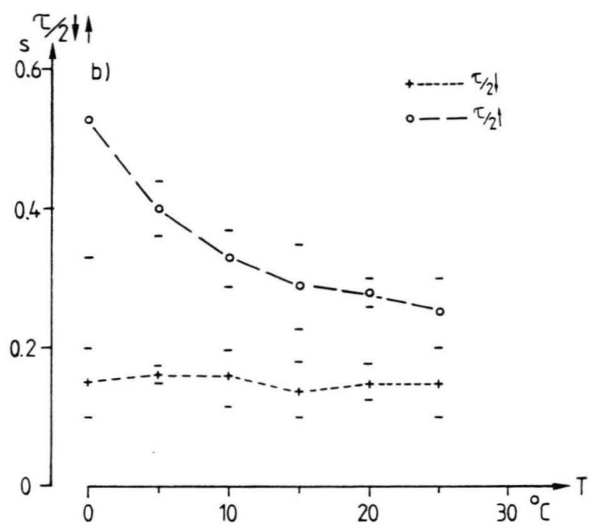

Fig. 11. Half-times for rising $\downarrow$ (+---.- + ) and declining $\tau / 2$

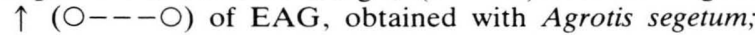
time of stimulation: $1 \mathrm{sec}$; stimulation interval: $60 \mathrm{sec}$; loading: $1.0 \mu \mathrm{g}(Z)$-5-decenyl acetate. The values presented are mean values and standard deviations out of five recorded values each.

Temperature dependence of the receptor potential (ESG)

In order to describe the receptor potentials, the same terms as in Fig. 9 are defined: A means now the maximum height of the receptor potential, $\tau / 2 \downarrow$ the time to the half maximum value of depolarization, and $\tau / 2 \uparrow$ that for the repolarization.

With a shorter duration of stimulation $(0.25 \mathrm{sec})$ the dependence of the receptor potential amplitude on the temperature shows an optimum curve, similar to that observed for EAG (Fig. 12).

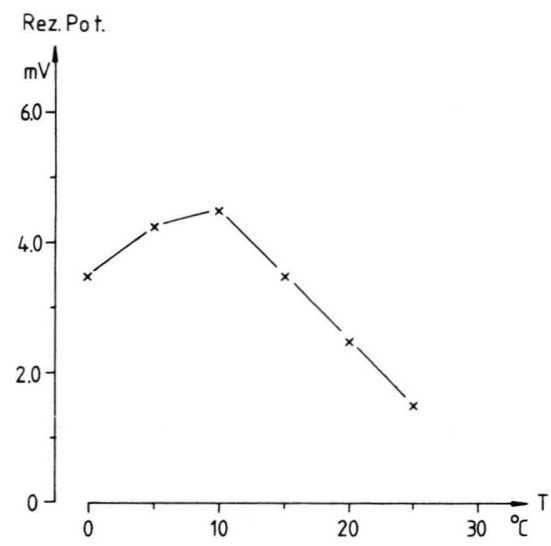

Fig. 12. Temperature dependence of receptor potential amplitude (Rez. Pot.) with Antheraea pernyi. Stimulation period: $0.25 \mathrm{sec}$; interval: $90 \mathrm{sec}$; stimulus source: $1 \mu \mathrm{g}$ (E)-6,(Z)-11-hexadecadienal. 
With a relatively longer period of stimulation of $10 \mathrm{sec}$, the amplitude of the receptor potential decreases almost linearly with increasing temperature, as it is shown with Fig. 13a. The time required for the depolarization and the repolarization are shorter with higher temperatures, and as a result asymptotic curves are obtained (Fig. 13b).
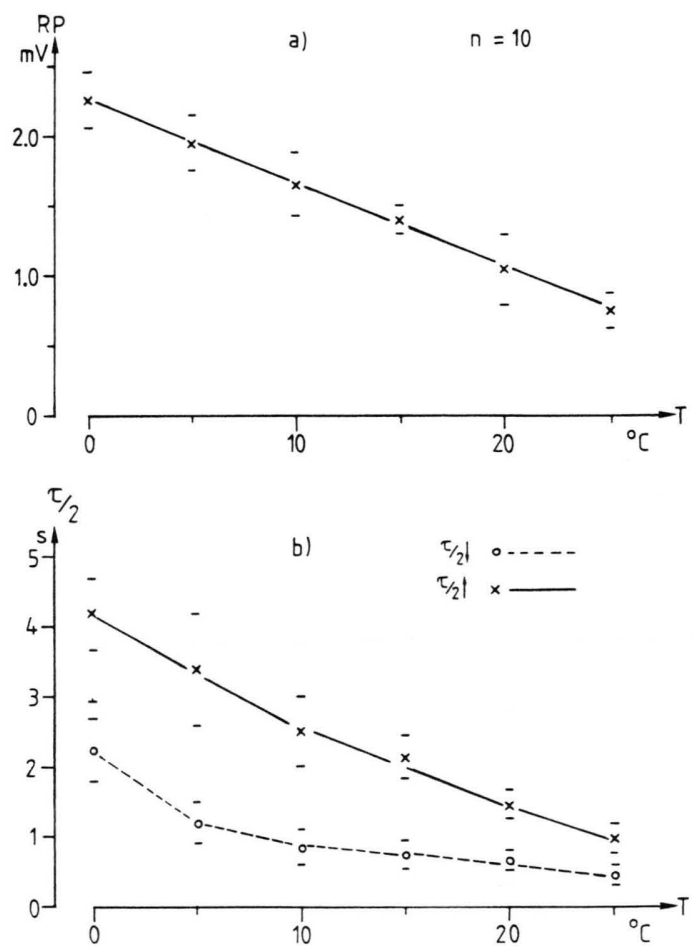

Fig. 13. Temperature dependence of a) the maximum amplitude of the receptor potential (Rez. Pot.) and of b) the half-width for depolarization $\left(\mathrm{O}_{-}-\mathrm{O}\right)$ and repolarization $(\times-\times)$, determined with Antheraea pernyi. Stimulation period: $10 \mathrm{sec}$; interval: $90 \mathrm{sec}$; stimulus source: $1.0 \mu \mathrm{g}(E)-6,(Z)-11$-hexadecadienal. Mean values from 10 experiments with standard deviations.

The maximum value of receptor potential amplitude, in the $0-25^{\circ} \mathrm{C}$ temperature range, was obtained at $0{ }^{\circ} \mathrm{C}$. However, this was valid only for sufficiently longer periods of stimulation $(15 \mathrm{sec})$. With shorter periods of stimulation the potential fails to reach the maximum value. In Fig. 14 the dependence of the receptor potential amplitude on the duration of the stimulation for temperatures of 0 and $10{ }^{\circ} \mathrm{C}$ is illustrated. Furthermore, from the figure it becomes evident, that the receptor potential remains constant after attaining its temperature-dependent maximum (Fig. 14), which means that obviously a steady state is obtained.

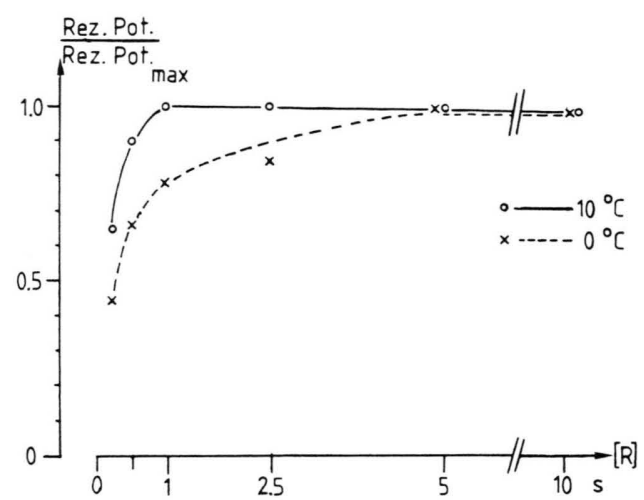

Fig. 14. Receptor potential amplitudes normalized with the maximum receptor potential value (Rez. Pot./Rez. Pot. max), dependent on the time of stimulation (R) at $0{ }^{\circ} \mathrm{C}$ and at $10{ }^{\circ} \mathrm{C}$, determined with Antheraea pernyi. Stimulus: $1.0 \mu \mathrm{g}(E)-6,(Z)-11$-hexadecadienal.

\section{Temperature dependence of action potential}

The action potentials obtained from the tips of a sensory hair also showed a temperature dependence. Positive amplitude between 6 and $2 \mathrm{mV}$ were obtained for temperatures between 0 and $25^{\circ} \mathrm{C}$.

However, by this technique of measuring, only somewhat restricted information can be obtained about the real shape of the action potential curves at their real site of formation. However, it allows qualitative statements to be made on the temperature dependence of values at half-width. For this purpose the following terms are introduced (Fig. 15): A amplitude of the positive phase; $\tau / 2$ value of the halfwidth.

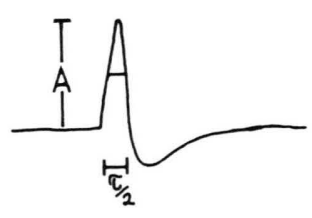

Fig. 15. Definitions for the terms for the description of the action potential shape. $A=$ amplitude of the positive phase, $\tau / 2=$ value of the half-width. 
To determine the exact duration of the action potentials, the ESGs were transferred from a tape recorder, which was allowed to run at a very slow mode, to a recorder. This way the half-width values could be measured. The values were $5,2,0.5$ and $0.25 \mathrm{msec}$ for temperatures $0,10,20$ and $30^{\circ} \mathrm{C}$, respectively (Fig. 16a.). The decrease of the duration of action potential shows an exponential behaviour and therefore can be represented as a straight line in an Arrhenius plot (Fig. 16b).

\section{Hysteresis effect of the ESG}

When temperature changes were carried out in $5{ }^{\circ} \mathrm{C}$ steps, as already described for EAG, and the electrosensillograms (ESG) released by a pheromone stimulation were recorded for each temperature step, a hysteresis effect was clearly evident from these optimum curves obtained from the number of

a)

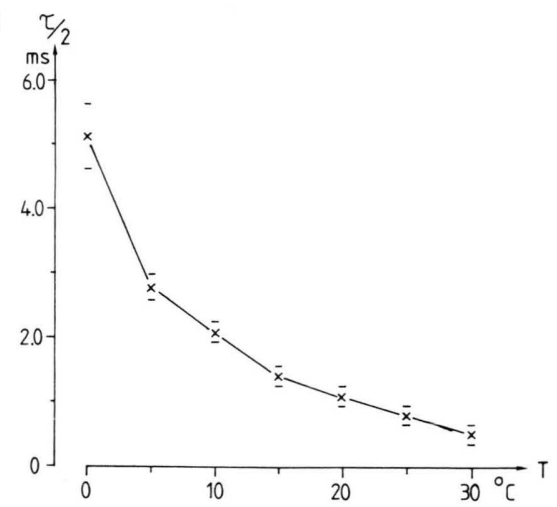

b)

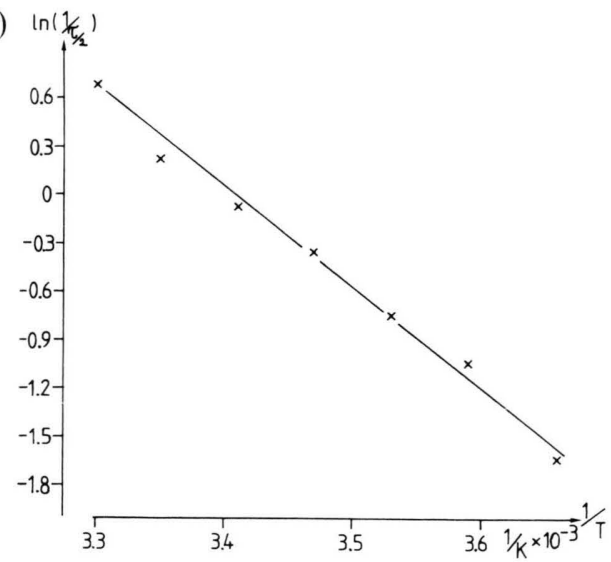

Fig. 16. Dependence of the half-width of the action potentials on the temperature, a) direct form, b) as an Arrhenius diagram. spikes released by a constant amount of stimulus. This number was higher for antennae that underwent a warmer temperature treatment than that for those subjected to colder pretreatment. Fig. 17 shows the effect of temperature on the summed-up number of action potentials during a stimulation of $10 \mathrm{sec}$ duration.

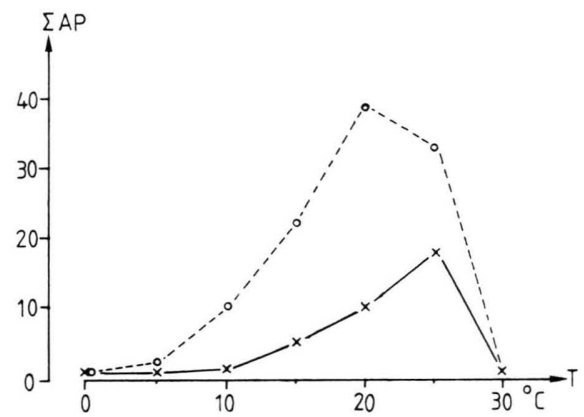

Fig. 17. Temperature dependence of the number of action potentials $(\Sigma \mathrm{AP})$ shown by Antheraea pernyi antennae. $\times \longrightarrow \times$, values recorded with increasing temperature, $\bigcirc---\bigcirc$, those consecutively recorded with decreasing temperature. Time of stimulation: $10 \mathrm{sec}$; stimulation interval: $90 \mathrm{sec}$; loading of stimulus source: $0.1 \mu \mathrm{g}(E)-6,(Z)$ 11-hexadecadienal.

The receptor potentials were not analyzed in this case, since the receptor potential amplitudes resulting from loading of the source with $0.1 \mu \mathrm{g} \mathrm{E6,Z11-}$ hexadecadienal were very small.

With higher loadings of the stimulus, e.g. $100 \mu \mathrm{g}$, a hysteresis effect was also evident in the receptor potential amplitudes, as it can be seen in Fig. 18. The preparate was first adapted to $10^{\circ} \mathrm{C}$ and then subjected to temperatures of $0{ }^{\circ} \mathrm{C}, 10{ }^{\circ} \mathrm{C}, 20^{\circ} \mathrm{C}$ and then back to $10{ }^{\circ} \mathrm{C}$, and at each temperature the antenna was stimulated by a constant amount of pheromone. With the receptor potentials as well as the number of action potentials, both obtained at $10{ }^{\circ} \mathrm{C}$, higher values were obtained from the measurements which had been carried out after pretreatment with higher temperature (Fig. 18).

The hysteresis effect was still present after the temperature cycle was repeated several times. Since within a given test series the higher readings of potentials were recorded after the lower values had been obtained. A temporary decrease of sensitivity of the preparation by adaptation could be excluded.

Fig. 19 shows the change of the receptor potential and the summation of number of induced action po- 

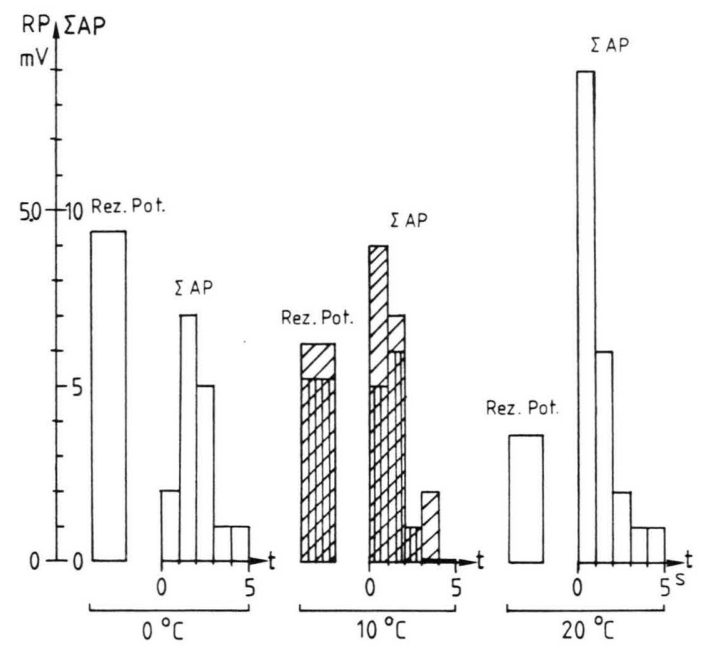

Fig. 18. Receptor potential amplitudes (Rez. Pot.) and number of action potentials ( $\Sigma$ AP) per second, obtained from Antheraea pernyi antennae at $0{ }^{\circ} \mathrm{C}$ and $20^{\circ} \mathrm{C}$. The vertically hatched columns represent the values at $10^{\circ} \mathrm{C}$, obtained after a $0{ }^{\circ} \mathrm{C}$ pretreatment. Time of stimulation: $5 \mathrm{sec}$; stimulus interval: $120 \mathrm{sec}$; stimulus source loading: $100 \mu \mathrm{g}$ of $(E)-6,(Z)$-11-hexadecadienal.

tentials observed during a $5 \mathrm{sec}$ stimulation at temperatures of $0{ }^{\circ} \mathrm{C}, 10{ }^{\circ} \mathrm{C}, 20^{\circ} \mathrm{C}$, and $10{ }^{\circ} \mathrm{C}$, respectively. It became evident that the receptor potential amplitude and the number of action potentials show an opposite type of dependence on temperature.

The receptor potential amplitude is smaller and the number of the thus induced action potentials is larger at higher temperatures. The phenomenon of hysteresis can be observed with the receptor potentials as well as with the number of action potentials in Fig. 19. The difference of the receptor potential measured at $10{ }^{\circ} \mathrm{C}$, depending on the temperature pretreatment is ca. $30 \%$. The difference shown by the number of action potentials is even more significant (about 40\%).

When the relative receptor potentials derived from Fig. $19 \mathrm{a}$, for the temperatures 0 and $20^{\circ} \mathrm{C}$, were replotted on a semilogarithmic scale, it became evident that the values for $20^{\circ} \mathrm{C}$ lie on a straight line, whereas those for $0{ }^{\circ} \mathrm{C}$ lie on two straight lines which intercept each other at $2 \mathrm{sec}$. This indicates the appearance of two different time constants (Fig. 20).

For the receptor potential evoked by $100 \mu \mathrm{g}$ aldehyde, the time required for reaching the halfmaximum value is $0.45 \mathrm{sec}$ at $20^{\circ} \mathrm{C}$, and $0.90 \mathrm{sec}$ at $0{ }^{\circ} \mathrm{C}$ (Fig. 20).

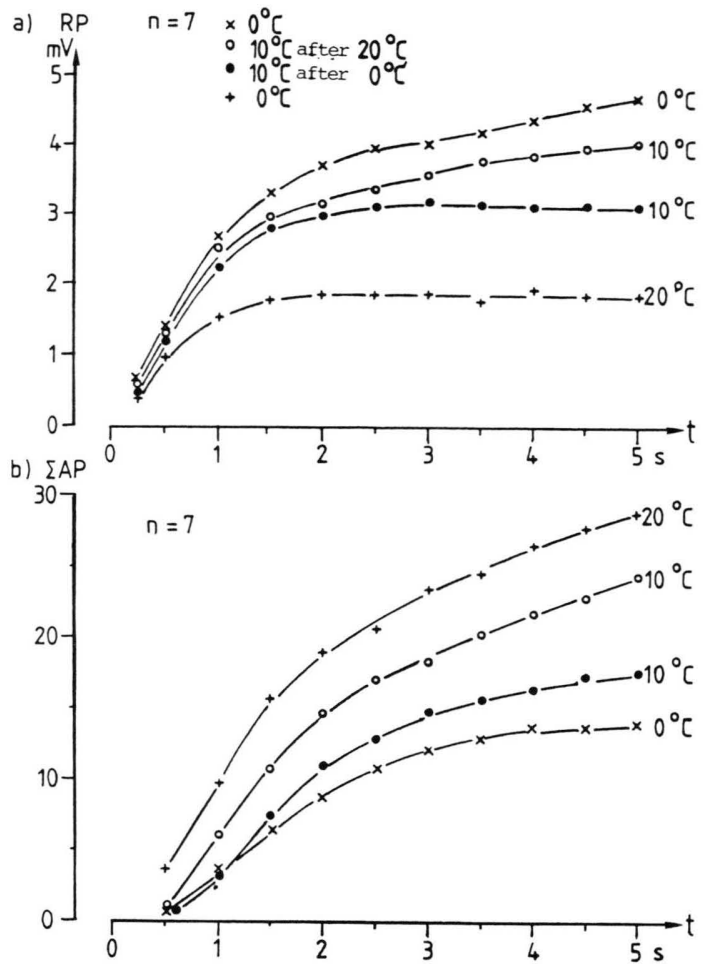

Fig. 19. Course of a) the receptor potential and b) the number of induced action potentials during a stimulation duration of $5 \mathrm{sec}$ at temperatures of $0{ }^{\circ} \mathrm{C}(\times-\times), 10^{\circ} \mathrm{C}$ after $0{ }^{\circ} \mathrm{C}(-\bullet), 20{ }^{\circ} \mathrm{C}(+-+), 10{ }^{\circ} \mathrm{C}$ after $20^{\circ} \mathrm{C}$ $(\mathrm{O}-\mathrm{O})$; determined with Antheraea pernyi. Values are mean values out of seven measurements. Stimulus interval: $120 \mathrm{sec}$; stimulus source loading: $100 \mu \mathrm{g}(E)-6,(Z)-11$ hexadecadienal.

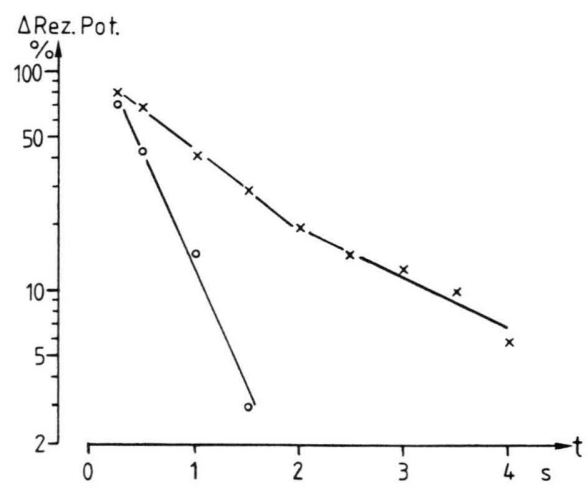

Fig. 20. Dependence of the relative receptor potential values on the stimulus duration at $0{ }^{\circ} \mathrm{C}(\times-\times)$ and $20^{\circ} \mathrm{C}$ $(\bigcirc-\bigcirc)$, studied with Antheraea pernyi. Values taken from Fig. 19a. 


\section{Discussion}

\section{Similarities in EAG and ESG measurements}

The investigations carried out in this study show many similarities between the results obtained from EAG and ESG. With gradual as well as stepwise temperature programs, the electroantennogram amplitudes plotted against the temperature gave optimum curves. Similarly, the potentials obtained after a short stimulation time by single sensillum recordings, for the amplitudes of the receptor potentials and for the number of action potentials (Figs. 12 and 17), showed the presence of an optimum temperature.

Furthermore, the effect of hysteresis was found in both recording techniques for all the species investigated, and also for different loadings of respective pheromones. The hysteresis effect could be observed for gradual as well as stepwise temperature programs (EAG: Fig. 7, 8; ESG: Fig. 17, 18, 19).

Further similarities between EAG and ESG were found in the temporal course of potential change as a function of temperature. The rate of change became faster with increasing temperature. This is shown by Fig. 10 for the EAG and Fig. 13 for the receptor potential. Similar observations showing the close relationship between EAG and ESG have been made by Nagai [8] with Ostrinia and Löfstedt et al. [9] with Dioryctria abitiella. But it has to be pointed out, that there are also differences between EAG and ESG [8, $10,11]$.

\section{Maxima in EAGs}

From Fig. 5 it can be seen, that with $1 \mathrm{sec}$ stimulation time the EAG amplitudes are dependent on temperature and the curves show a maximum. However, for the same temperature range the duration of the EAG responses becomes shorter towards higher temperatures, and the half-width value of the EAG signals become narrower (Fig. 10) and shows no maximum. The half-width values are determined mainly for the declining phase (Fig. 11). The rising phase shows only a small temperature dependence. From this it becomes evident, that both phases are based upon different processes with different temperature dependences.

The $\mathrm{Q}_{10}$-values obtained from Fig. 5 vary between 1.0 and 2.1, and have an average value of 1.6 for the temperature range 0 to $10{ }^{\circ} \mathrm{C}$. Since the $\mathrm{Q}_{10}$-values known for physical processes and simple diffusion lie between 1.03 to 1.30 [12], our results do imply that the temperature-dependent rate of diffusion of pheromone molecules towards the dendrite membrane can be excluded as an explanation of the increase of amplitude in the lower temperature range.

\section{Receptor potential}

The maximum amplitude of the receptor potential shows a near linear decrease with the increasing temperature (Fig. 13a). Uehara and Morita [13] have demonstrated with labellary chemoreceptors of Phormia regina that the receptor potentials for glucose and $\mathrm{NaCl}$ increase with increasing temperatures, whereas that for water was independent on temperature. However, the rate of increase of the receptor potentials for all three substances tested decreased with increasing temperature. These results are in agreement with our observations of the temperature-dependent rise and fall of receptor potential (Fig. 13b). For example, the half-width values for the depolarization at $0{ }^{\circ} \mathrm{C}$ is about $2.3 \mathrm{sec}$; this becomes smaller with increasing temperature, and at $30{ }^{\circ} \mathrm{C}$ it is only about $0.5 \mathrm{sec}$. A similar tendency has been observed with receptor potentials deduced from Pacini bodies of cats. In this case the duration of rise and fall of the amplitudes measured between 10 and $40{ }^{\circ} \mathrm{C}$ do decrease by about $50 \%$ [14].

Studies conducted on stretching muscle of the crab Pachygrapsus crassipes are also of interest in this respect [15]; with increasing temperature a decrease of the amplitude of the excitory synaptical potentials has been observed. The time required to attain the respective maximum amplitude becomes shorter with increasing temperature. The maximum is reached faster at higher temperatures, similar to the result obtained in our study (Fig. 14).

Our present knowledge of the complicated electric relations in nerve cells provides no definitive explanation about the decrease of the maximum amplitude of the receptor potential with increasing temperature. It is known that with increasing temperature the resistance of a sensilla membrane decreases [16] and thereby the conductivity increases according to the definition. By this reasoning, increasing temperature can lead, at least in principle, to a decline of the maximum amplitude. The latter reflects the relative change of conductivity induced by the interaction between signal molecule and receptor region. 
If the assumption is made that there is a correlation between the receptor potential and the opening of individual ion channels $[17,18]$, the decline of the maximum amplitude of the receptor potential by increasing temperature may result from a decline of time of opening and degree of opening respectively of the individual channel.

This has been proven by Anderson et al. [19], with glutamate-induced ion channels of grasshoppers; and by Fischbach and Lass [20], with muscles of chick embryos.

These authors presume that the state of lipids in the immediate environment of the ion channel influences its mode of action [19], and that the fluidity of the membrane lipids associated with the "microenvironment" of the acetylcholine receptor decisively determines its degree of opening [20].

These presumptions are supported by the works of Romey et al. [21], on the electrical activity of ion channels in nerve membranes.

Our present results point in the same direction and confirm our former supposition that the signal molecules interact with the receptor region in a flexible manner and the receptor region consists of proteins as well as lipid regions $[3,4]$.

\section{Hysteresis}

By passing through a temperature cycle of $0{ }^{\circ} \mathrm{C}$ to $20{ }^{\circ} \mathrm{C}$ or $35^{\circ} \mathrm{C}$, respectively, and back to $0{ }^{\circ} \mathrm{C}$, we observed a phenomenon of hysteresis, i.e. two different values for each temperature, depending on the cold or warm pretreatment experienced by the antenna. The values obtained after a warm pretreatment were higher than those after a cold treatment. This was valid for both EAG as well as for receptorpotential amplitudes. A similar hysteresis effect was found for the total number of action potentials released by a constant amount of stimulus.

With the stepwise temperature program, the preparation had up to $100 \mathrm{sec}$ to adapt to the new temperature. Because of the small dimensions of the sensilla $(1=300 \mu \mathrm{m} ; \varnothing=4 \mu \mathrm{m})$ one can assume, that the whole sensillum has attained the set environmental temperature before the beginning of the pheromone stimulation. Therefore, the ratio of adsorption and desorption, as well as the rate of diffusion are the same at the test temperature, irrespective of the pretreatment the antenna had experienced. Thus such effects can be excluded as the reason for the hy- steresis. Hence the hysteresis found here can be attributed to processes which may be participating in the transduction.

The temperature dependence of activation and desactivation of the sodium ion-current, in different preparations made by Schwarz [22] and Benndorf and Nilius [23] has also shown a hysteresis curve. These authors have given the change of fluidity of the lipids, surrounding the receptor or the channel protein, as an explanation. They prefer this explanation over that of a change in the protein itself. This supports the possibility discussed in the previous section, that the fluidity of the membrane lipids which are directly associated with the protein of a receptor region will have an influence on the degree, time, and rate of opening of the ion channels.

The appearance of hysteresis can be taken as an indication for the presence of phase transitions to which especially meta-stable states and domain structures are contributing [24-26] (compare also, hysteresis with lipid membranes: [27, 28] and the references therein).

The integral proteins of a membrane are integrated into a rigid layer of lipids which can be visually imagined as floats swimming in a lake of fluid lipids $[21,26]$. These protein lipid domains can represent cooperative systems, in which a change of conformation in the lipid part will course a simultaneous change of conformation in the protein part [26].

In the rigid quasi-cristalline phase, the $\mathrm{H}$-atoms of the fatty acids form a hexagonal most-compact spherical packing, in which holes exist due to gauche conformations in the chain. As the transition to the fluid phase occurs, the number of gauche conformations increases rapidly $[28,29]$. In a cooperative lipid-protein domain, these changes of conformations appearing first in the phase transitions of the lipid part should be then transferred to the protein component. Lipid-phase transitions can be released isothermally by changes of charge in the hydrophobic head groups of the lipids, and especially, also by "foreign" molecules [26, 29], even more when the lipid part is in a meta-stable state.

On the above-stated assumption that there is a direct correlation between the receptor potential and the number of activated ion channels, and the opening width or the opening time, respectively, the following model can be proposed as a possible explanation of hysteresis phenomena, by taking into consideration the hitherto-discussed results of other 
groups, as well as those of ours, that the boundary area between protein and lipid plays a role in the molecular process leading to the formation of an ion channel.

The signal molecule during its attachment interacts with the boundary area mentioned above, in which the lipid part exists in a meta-stable state. The part of the stimulus molecule which comes into contact with the lipid region of the domain acts as a foreign body which initiate a change of phase (change of conformation) at the place of the interaction, which spreads out cooperatively and thus induces the formation of an ion channel [4]. The formation of meta-stable states in lipids is more favourable when approaching from a warmer temperature than a colder. This can explain our hysteresis results, in which the values, obtained after a warmer temperature pretreatment were always higher than those from a colder pretreatment.

It should be pointed out that the conceptions developed here represent only a working hypothesis, which can for the moment explain to a reasonable degree most of the results of temperature dependence of our measurements.

\section{Schematic representations of molecular processes at the dendrite of a sensory cell}

In the following section, the molecular processes which occur when a pheromone interacts with the receptor regions will be discussed using a simplyfied scheme based on various experimental results. For this model, we will use $\mathrm{P}$ for pheromone and $\mathrm{E}$ for receiver, instead of more generally used $\mathrm{S}$ for signal and $\mathrm{R}$ for receptor because the use of $\mathrm{R}$ and $\mathrm{S}$ is well established in chemical nomenclature to designate absolute configuration. Lateron the model discussed

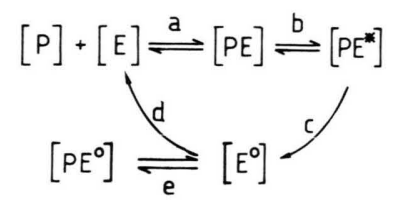

Fig. 21. Schematic presentation of pheromone receptor interaction: $[\mathrm{P}]=$ pheromone, $[\mathrm{E}]=$ receptor, $[\mathrm{PE}]=$ pheromone receptor complex, $\left[\mathrm{PE}^{*}\right]=$ activated complex, $\left[\mathrm{P}^{\circ}\right]=$ desactivated pheromone, $\left[\mathrm{E}^{\circ}\right]=$ non-activable receptor, $\left[\mathrm{PE}^{\circ}\right]=$ non-activable pheromone receptor complex, a, b, c, d and $\mathrm{e}=$ reaction rate constants. here will also be extended to chiral pheromone derivatives [30].

Pheromone $[\mathrm{P}]$ and receptor $[\mathrm{E}]$ form a complex $[\mathrm{PE}]$ by a reversible reaction. The complex [PE] will change over to an activated complex [PE*], probably representing the opened channel. These presumptions are based on considerations of Del Castillo and Katz [31] put forward for the acetylcholine receptor. Kaißling has discussed for pheromones these presumptions in detail for each individual step [32-34]. Based on these considerations and numerous calculations, a rapid inactivation of the pheromone must be expected at an earlier stage [35]. A binding protein found in the lymphe of sensilla $[34,36,37]$ may be responsible for this rapid inactivation.

It seems plausible that the changes of conformation that occur in the receptor region, when the transition from [PE] to [PE*] takes place weakens the binding of $[\mathrm{P}]$ to $[\mathrm{E}]$ in such a way that the binding protein is able to remove the pheromone from the complex and transport it away $\left[\mathrm{P}^{\circ}\right]$. At the same time or later, the enzymatic metabolism of the pheromone [36, 38, 39], as found in certain cases, can take place. The receptor is then left in a form $\left[\mathrm{E}^{\circ}\right]$ which cannot be activated, but can react again with a pheromone molecule to form the complex $\left[\mathrm{PE}^{\circ}\right]$. The formation of $\left[\mathrm{PE}^{\circ}\right]$ does not lead to an opening of an ion channel. $\left[\mathrm{E}^{\circ}\right]$ itself can be reactivated to [E].

We have incorporated $\left[\mathrm{E}^{\circ}\right]$ into the scheme given in Fig. 21 based on the assumptions of Katz and Thesleff [40], who presume that the appearance of a non-activable receptor species can be used to explain the phenomenon of adaptation ( $c f$. also [33]).

The transition from $\left[\mathrm{PE}^{*}\right]$ to $\left[\mathrm{E}^{\circ}\right]$ and $\left[\mathrm{P}^{\circ}\right]$ thus represents a desensitivation process and that from $\left[\mathrm{E}^{\circ}\right]$ to $[\mathrm{E}]$ a resensitivation.

All rate constants given in Fig. 21 should be temperature-dependent. The slower increase of receptor potential at $0{ }^{\circ} \mathrm{C}$, compared to that of $10{ }^{\circ} \mathrm{C}$, as shown in Fig. 14, can be explained in the following way: At lower temperatures the rate constants a and $b$ become smaller, resulting in a slower rate of transformation of chemical stimulation at the receptor into an ion current.

The plateau of the receptor potential in Fig. 14 represents a steady state for which the number of opened ion channels [ $\left.\mathrm{PE}^{*}\right]$ per time unit is constant. The decrease of steady-state amplitudes with increasing temperature (Fig. 13a) can be explained by the 
fact that the rate constant $\mathrm{c}$ increases faster than the constants a and b. This in turn results in a smaller number of opened ionic channels in the steady state. The appearance of two rate constants in Fig. 20 is the object of further investigations.

[1] Pheromones, 69: H. J. Bestmann, T. Zeibig and O. Vostrowsky, Synthesis 1989, in press.

[2] Preceding paper: H. J. Bestmann and K. Dippold, Naturwissenschaften 70, 47 (1983).

[3] a) H. J. Bestmann, P. Rösel, and O. Vostrowsky, Liebig's Ann. Chem. 1979, 1189; b) H. J. Bestmann and O. Vostrowsky, in: Olfaction and Endocrine Regulation (W. Breipohl, ed.), p. 253, IRL London 1982.

[4] H. J. Bestmann, Verh. Ges. Dtsch. Naturforscher Ärzte (113. Versammlung, Nürnberg 1984) 1985, 301.

[5] D. Schneider, Z. vergl. Physiologie 40, 8 (1957); Jahrbuch der Max-Planck-Gesellschaft 1963, 150.

[6] K. E. Kaißling, in: Biochemistry of Sensory Functions (L. Jaenicke, ed.), p. 243, Springer Verlag, Berlin, Heidelberg, New York 1974; Abstr. 1st Congr. ECRO, Paris 1974, p. 26.

[7] K. E. Kaißling and J. Thorson, in: Receptors for Neurotransmitters, Hormones and Pheromones in Insects (D. B. Satelle), p. 261, Elsevier: North-Holland Biomedical Press 1980.

[8] T. Nagai, Arch. Insect Biochem. Physiol. 1, 85 (1983).

[9] C. Löfstedt, J. N. C. van der Pers, J. Lofqvist, and B. S. Lanne, Ent. Exp. Appl. 34, 20 (1983).

[10] K. E. Kaißling, in: Chemical Ecology: Odor Communication in Animals (F. J. Ritter, ed.), p. 43, Elsevier, Amsterdam 1979.

[11] J. N. C. Von Der Pers, G. Thomas, and C. J. Den Otter, Chem. Senses 5, 367 (1980).

[12] H. Lullies, in: Kurzgefaßtes Lehrbuch der Physiologie (W. D. Keidel, ed.), 14.1, Thieme Verlag, Stuttgart 1975.

[13] S. Uehara and H. Morita, J. Gen. Physiol. 59, 213 (1972).

[14] N. Ishiko and W. R. Löwenstein, J. Gen. Physiol. 45, 105 (1961).

[15] P. J. Stevens and H. L. Atwood, J. Comp. Physiol. 142, 309 (1981).

[16] J. J. De Kramer, J. Neurosci. 5, 2484 (1985).

[17] Compare critical comments J. J. De Kramer and J. Hemberger, in: Pheromone Biochemistry (G. D Prestwich and A. J. Blomquist, eds.), p. 433 , Academic Press, Inc. 1987.

[18] K. E. Kaißling, Recognition of pheromones by moth especially in Saturniids and Bombyx mori, in: Chemical Ecology: Odor Communication in Animals (F. J. Ritter, ed.), pp. 43-56, Elsevier, Amsterdam 1979.

[19] C. R. Anderson, S. G. Cull-Candy, and R. Miledi, Nature 268, 663 (1977).

[20] G. D. Fischbach and Y. Lass, J. Physiol. 280, 527 (1978).

\section{Acknowledgements}

We thank the Deutsche Forschungsgemeinschaft for financial support of these studies, and Prof. Dr. G. Seitz, Prof. Dr. K. E. Kaißling and Dr. J. De Kramer for many critical discussions.

[21] G. Romey, R. Chicheportiche, and M. Lazdunski, Biochem. Biophys. Acta 602, 610 (1980).

[22] W. Schwarz, Pflügers Archiv 382, 27 (1979).

[23] K. Benndorf and B. Nilius, Pflügers Archiv 400, 329 (1984).

[24] A. R. Ubbelohde, in: Reactivity of Solids (J. H. de Boer, ed.), Elsevier, Amsterdam 1961; Melting and cristall structure, Claredon Press, Oxford 1965.

[25] E. Neumann, Angew. Chem. 85, 430 (1973); Angew. Chem. Int. Ed. Engl. 12, 356 (1973).

[26] E. Sackmann, in: Biophysik (W. Hoppe et al., eds.), p. 439, Springer Verlag, Berlin, Heidelberg, New York 1982.

[27] L. Thrams, W. D. Klabe, and E. Boroske, Biophys. J. 42, 285 (1983).

[28] E. S. Rowe, Biochim. Biophys. Acta 813, 321 (1975).

[29] H. Träuble, Naturwissenschaften 58, 277 (1971).

[30] H. J. Bestmann, L. Hirsch, H. Platz, M. Rheinwald and O. Vostrowsky, Angew. Chem. 92, 492 (1980); Angew. Chem. Int. Ed. Engl. 19, 475 (1980).

[31] J. Castillo und B. Katz, Proc. Roy. Soc. 146, 369 (1957).

[32] K. E. Kaißling, in: Olfaction and Taste III (C. Pfaffmann, ed.), Rockefeller University, New York 1969; Olfaction and Taste VI (J. Le Magnen and P. McLeod, eds.), p. 9, Information Retrivial, London 1977; in: Biophysik (W. Hoppe et al., eds.), p. 722, Springer Verlag, Berlin, Heidelberg, New York 1982.

[33] C. Zack, Dissertation, Ludwig-Maximilian-Universität, München 1979.

[34] K. E. Kaißling, Ann. Rev. Neurosci. 9, 121 (1986).

[35] K. E. Kaißling, in: Olfaction and Taste IV (D. Schneider, ed.), p. 207, Wissenschaftl. VerlagsGesellschaft, Stuttgart 1972.

[36] R. G. Vogt and M. L. Riddiford, Nature 293, 161 (1981); in: Regulation of Insect Development and Behaviour (A. Sehnal et al., eds.), p. 955, Polytechnical University of Wrocław Press, Wrocław 1981; R. G. Vogt, Thesis, University of Washington, Seattle 1984.

[37] K. E. Kaißling, U. Klein, J. J. de Kramer, T. A. Keil, S. Kananjia, and J. Hemberger, in: Molecular Basis of Nerve Activity (J. P. Changeux et al., eds.), p. 1, De Gruyter Verlag, New York 1985.

[38] G. Kasang, in: Gustation and Olfaction (G. Ohloff and A. F. Thomas, eds.), p. 245, Academic Press, London, New York 1971.

[39] S. M. Ferkovich, M. S. Mayer, and R. R. Rutter, Nature 242, 53 (1973); J. Insect Physiol. 19, 2231 (1973).

[40] B. Katz and S. Thesleff, J. Physiol. 138, 63 (1957). 